\title{
Prospective randomised comparison between thrombolysis, rescue PTCA, and primary PTCA in patients with extensive myocardial infarction admitted to a hospital without PTCA facilities: a safety and feasibility study
}

F Vermeer, A J M Oude Ophuis, E J vd Berg, L G Brunninkhuis, C J Werter, A G Boehmer, A H Lousberg, W R Dassen, F W Bär

\begin{abstract}
Objective-To assess the safety and feasibility of acute transport followed by rescue percutaneous transluminal coronary angioplasty (PTCA) or primary PTCA in patients with acute myocardial infarction initially admitted to a hospital without PTCA facilities.

Design-In a multicentre randomised open trial, three regimens of treatment of acute large myocardial infarction were compared for patients admitted to hospitals without angioplasty facilities: thrombolytic treatment with alteplase (75 patients), alteplase followed by transfer to the PTCA centre and (if indicated) rescue PTCA (74 patients), or transfer for primary PTCA (75 patients).

Results-Between 1995 and 1997224 patients were included. Baseline characteristics were distributed evenly. Transport to the PTCA centre was without severe complications in all patients. Mean (SD) delay from onset of symptoms to randomisation was 130 (75) minutes and from randomisation to angiography 90 (25) minutes. Death or recurrent infarction within 42 days occurred in 12 patients in the thrombolysis group, in 10 patients in the rescue PTCA group, and in six patients in the primary PTCA group. These differences were not significant. Conclusions-Acute transfer for rescue PTCA or primary PTCA in patients with extensive myocardial infarction is feasible and safe. Efficacy of rescue PTCA or primary PTCA in this setting will have to be tested in larger series before this approach can be implemented as "routine treatment" for patients with extensive myocardial infarction.

(Heart 1999;82:426-431)
\end{abstract}

Keywords: myocardial infarction; percutaneous transluminal coronary angioplasty; primary PTCA; rescue PTCA; reperfusion

Kerkrade, Netherlands A G Boehmer

Correspondence to: Dr Vermeer.

email: F.Vermeer@

cardio.azm.nl

Accepted for publication 23 March 1999 opening of the occluded coronary artery in acute myocardial infarction is the key factor determining clinical outcome. ${ }^{1}$ Because thrombosis is the most common cause for the obstruction, thrombolysis has become the treatment of choice. This treatment has shown to be reasonably effective. Patency of the culprit vessel (TIMI 2 or 3 flow) can be achieved in $50-90 \%$ of cases at 90 minutes after start of treatment. However, side effects of thrombolytic treatment are severe bleeding complications like intracranial haemorrhage. ${ }^{2-5}$

Primary percutaneous transluminal coronary angioplasty (acute PTCA without previous administration of thrombolytic treatment) has been shown to be a safe and successful alternative to thrombolytic treatment. After primary PTCA patency rates above $90 \%$, with low incidence of complications, have been reported. ${ }^{6-9}$ Recently, several randomised studies reported that primary PTCA is more effective than thrombolytic treatment. ${ }^{10-13}$ However, none of these studies included a treatment arm in which rescue PTCA (PTCA after failed thrombolysis) was part of the protocol.

So far, the published results of rescue PTCA (acute PTCA after failed thrombolysis) have been equivocal. A high complication rate was described in several retrospective studies. ${ }^{14-17}$ The RESCUE study prospectively evaluated rescue PTCA in patients with anterior infarction. ${ }^{18}$ The findings of the RESCUE study and several other studies support the suggestion that an invasive strategy in patients with acute myocardial infarction might contribute to an improved clinical outcome. ${ }^{19-21}$

The conclusions concerning PTCA as mentioned above are limited to patients directly admitted to a hospital with PTCA facilities. The optimal strategy for patients initially admitted to a hospital without PTCA facilities remains unclear. The relative safety of transferring patients with acute myocardial infarction to a PTCA centre for primary PTCA or for rescue PTCA has been described in retrospective studies, ${ }^{22}{ }^{23}$ but prospective studies are lacking.

Our study is the first to compare prospectively the outcome of thrombolysis, primary PTCA, and thrombolysis followed by rescue PTCA (if indicated) for patients with extensive myocardial infarction initially admitted to a hospital without PTCA facilities. It was designed as a pilot study to test the safety and feasibility of acute transport to the nearest PTCA centre for patients with acute myocardial infarction. For this reason the outcome of 
the patients who underwent or were allocated to immediate transport was compared to the outcome of those patients allocated to receive thrombolytic treatment without transport to the PTCA centre.

\section{Methods}

DESIGN

Three therapeutic regimens in the treatment of acute myocardial infarction were compared in this open randomised trial: thrombolytic treatment; primary PTCA; and thrombolytic treatment followed by acute angiography and rescue PTCA (if indicated). All participating centres to which the patients were initially admitted had no PTCA facilities. Patients with extensive acute myocardial infarction were candidates for the study if they had no contraindications for thrombolytic treatment. From all eligible patients who gave informed consent a fax of the ECG with the patient's initials and date of birth was sent to the coronary care unit of the PTCA centre. Randomisation was done by computer. The fax from the PTCA centre back to the referring centre with the treatment allocation was considered to be the irrevocable entry in the study. Patients allocated to thrombolytic treatment received alteplase and stayed in the hospital where they were initially admitted. Patients allocated to primary or rescue PTCA underwent immediate transport to the PTCA centre. The transport was operated by the ambulance services by well trained paramedic staff in ambulances equipped to transfer critically ill patients. A 24 hour service was available in the PTCA centre for acute angiography with two catheterisation rooms. Patients were transferred back to the referring centre the next day. If no bed was available, patients were transferred back after angiography as soon as their clinical situation had stabilised. Patient recruitment was completed within two years.

\section{END POINTS}

The primary end point of this pilot study was to test the safety and feasibility of acute transport to a PTCA centre for patients with acute myocardial infarction. The combined incidence of death and recurrent myocardial infarction within the first 42 days was considered to be a secondary end point and was used to compute the required sample size for a study to test the efficacy of these treatment strategies. Other end points were: mortality; recurrent infarction; thromboembolic and haemorrhagic stroke; recurrent interventions such as PTCA or coronary artery bypass grafting (CABG); recurrent ischaemia during one year follow up; coronary patency; bleeding complications; complications caused by the transport to and from the PTCA centre; and differences in delay to start of treatment, especially delay related to transport to the PTCA centre. Recurrent infarction was defined as a new episode of chest pain occurring at least 48 hours after the initial infarction, accompanied by ECG changes and by a new rise in serum enzymes. The diagnosis of stroke was confirmed by the neurologist, and the origin of the stroke was confirmed by com- puted tomography. Recurrent ischaemia was defined as a new episode of chest pain at least 48 hours after the initial infarction with transient ECG changes and without an enzyme rise.

PARTICIPATING CENTRES

Seven centres in Limburg, a province in the south of the Netherlands, participated in the study. The distance between the referring centres and the PTCA centre (Maastricht) varied from $25 \mathrm{~km}$ (Sittard) to $50 \mathrm{~km}$ (Roermond).

\section{PATIENT SELECTION}

Inclusion criteria were: age less than 80 years; first or recurrent myocardial infarction; chest pain lasting for at least 30 minutes not responding to nitrates; and onset of chest pain less than six hours before randomisation. The following ECG criteria had to be fulfilled: ST segment deviation (elevation in at least one lead + depression) of at least $1.5 \mathrm{mV}$ $(=15 \mathrm{~mm})$. Exclusion criteria were: severe hypertension unresponsive to acute treatment; enhanced risk of bleeding; stroke in the last 12 months; cardiogenic shock; severe concomitant disease affecting life expectancy; a priori known logistic problems for transport or angiography (transport to the PTCA centre should be feasible within one hour after randomisation); no informed consent; and anticipation of incomplete follow up.

\section{MEDICATION}

The thrombolytic agent alteplase (accelerated regimen) was given immediately after randomisation. For the patients allocated to rescue PTCA the alteplase bolus was given and the alteplase infusion started before the ambulance transport. The alteplase infusion was continued during transport and upon arrival at the PTCA centre. In the majority of cases the alteplase infusion was completed (at $90 \mathrm{~min}$ utes) before the start of angiography. Heparin was given as an intravenous bolus of $5000 \mathrm{U}$ before the administration of alteplase, or as an intravenous bolus of $10000 \mathrm{U}$ for patients allocated to primary PTCA. A second heparin bolus of $5000 \mathrm{U}$ was given at the start of the acute coronary angiogram, and a third bolus of $5000 \mathrm{U}$ was given after completion of the PTCA procedure (if applicable). After infusion of the thrombolytic agent or after acute coronary angiography a heparin infusion was started with the dosage titrated against the partial thromboplastin time (prolongation two to three times) for 24 hours. Acetylsalicylic acid (300 mg intravenously or $160 \mathrm{mg}$ orally) was administered before initiation of thrombolytic treatment, followed by $80 \mathrm{mg}$ of oral aspirin daily unless contraindicated. A nitrate infusion titrated against blood pressure was started and continued for 24 hours. The patients were not treated with abciximab. All other medication was at the discretion of the investigator.

\section{PRIMARY PTCA}

PTCA was performed at the site of the culprit lesion only. PTCA was attempted in all cases of TIMI $0 / 1$ flow unless the angiographic findings 


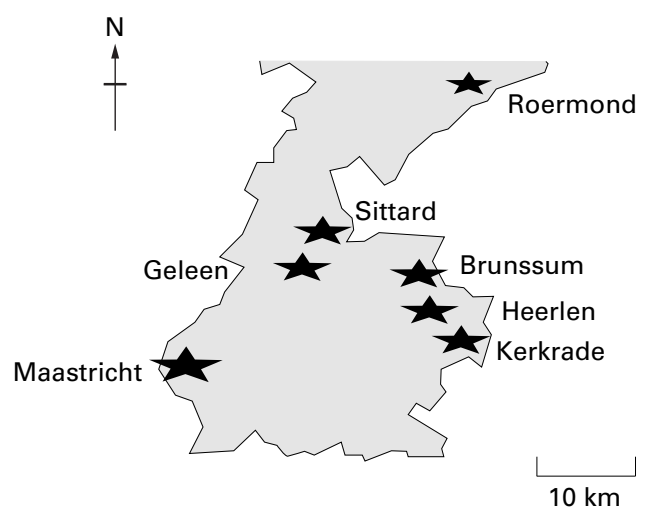

Figure 1 Location of the participating hospitals. All participating centres are located in the Limburg province in the Netherlands; on the west and south side is the border with Belgium, and on the east side is the border with Germany.

favoured acute CABG. In cases of TIMI 2 flow the decision to perform PTCA was made by the angiographer. In cases of TIMI 3 flow PTCA was not performed unless the clinical condition of the patient required such a procedure. In the event of a severe dissection or incomplete result of the PTCA a coronary stent was implanted. Successful PTCA was defined as TIMI 3 flow and stenosis $<50 \%$ at the end of the procedure.

RESCUE PTCA

In patients allocated to rescue PTCA the same procedure was followed in the catheterisation laboratory as for patients allocated to primary PTCA. The angiographer was not blinded to the treatment allocation. Rescue PTCA was defined as acute PTCA performed in patients with TIMI 0 or 1 flow at the angiogram performed (60 to approximately 120 minutes) after intravenous administration of the thrombolytic agent.

DATA ANALYSIS

The primary analysis was on intention to treat basis. All patients allocated to one of the three treatment regimens in response to the fax received at the PTCA centre were included in the analysis. If applicable, Fisher's exact test was used; two sided p values are reported.

\section{Results}

BASELINE CHARACTERISTICS

Between September 1995 and August 1997 a total of 224 patients with acute myocardial infarction were included in the study; 75 patients were allocated to thrombolytic treatment, 74

Table 1 Baseline characteristics (number of patients)

\begin{tabular}{llll}
\hline & Thrombolysis & $\begin{array}{l}\text { Thrombolysis }+ \text { rescue } \\
\text { PTCA }\end{array}$ & $\begin{array}{l}\text { Primary } \\
\text { PTCA }\end{array}$ \\
\hline Number of patients & 75 & 74 & 75 \\
Age (years) (mean (SD)) & $59(11)$ & $59(12)$ & $58(11)$ \\
Male & 56 & 57 & 54 \\
Female & 19 & 17 & 21 \\
Anterior MI & 36 & 37 & 34 \\
Inferior MI & 39 & 37 & 41 \\
Previous MI & 13 & 15 & 9 \\
Previous PTCA/CABG & 3 & 2 & 1 \\
Previous angina & 2 & 6 & 4
\end{tabular}

MI, myocardial infarction.

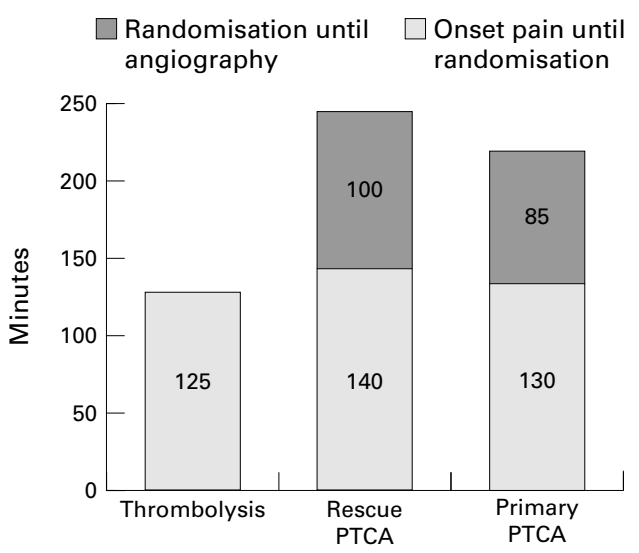

Figure 2 Mean treatment delay (minutes) from onset of chest pain to randomisation, and from randomisation to start of angiography for the rescue PTCA and the primary PTCA group.

patients to thrombolysis and rescue PTCA (if indicated), and 75 patients to primary PTCA. Inclusion was limited to the hospitals in the southern part of the Limburg province in the Netherlands (fig 1). Only patients with extensive ischaemia (total ST segment elevation and depression at least $1.5 \mathrm{mV}$ or $15 \mathrm{~mm}$ ) were included. This resulted in a relatively large proportion of patients with anterior infarction. All baseline characteristics were distributed evenly over the three treatment groups (table 1).

TREATMENT DELAY

Mean (SD) interval from onset of symptoms to randomisation varied from 125 (80) minutes in the thrombolysis group to 140 (70) minutes in the rescue PTCA group. Mean interval between randomisation and start of angiography in the PTCA centre was 85 (25) minutes in the primary PTCA group, and 100 (30) minutes in the rescue PTCA group (fig 2). On average PTCA was started 15 minutes after start of coronary angiography. Patency of the infarct related coronary artery was obtained within four hours after onset of symptoms in the majority of patients. Hospital admission was on average 90 minutes after the onset of chest pain. In the thrombolysis group and in the rescue PTCA group the thrombolytic treatment was initiated on average 10 minutes after randomisation - that is, on average 45 minutes after hospital admission. There were no significant differences in the treatment delays between the three treatment groups.

COMPLICATIONS DURING TRANSPORT

Immediately after randomisation, patients allocated to the primary PTCA or the rescue PTCA group were transferred to the PTCA centre, located at a distance of 25-50 km from the referring hospital (fig 1), usually by the same ambulance that had taken care of the transfer of the patient to the hospital. Before the transfer all patients received aspirin, a heparin bolus, and an infusion of glyceryl trinitrate; patients allocated to the rescue PTCA group also received a bolus and infusion of alteplase. Travel time in the ambulance lasted on average 20 minutes and did not exceed 30 


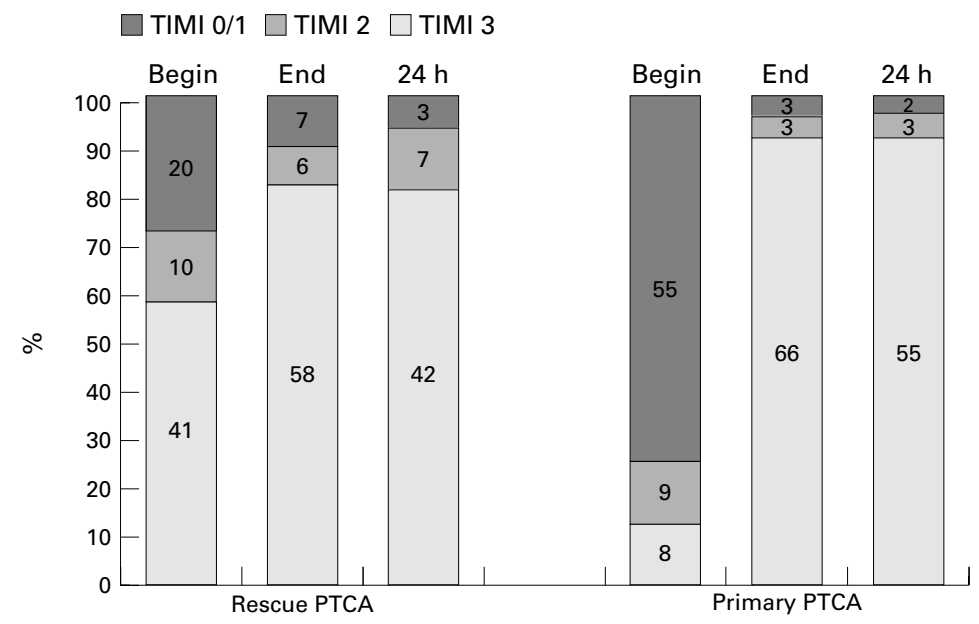

Figure 3 TIMI flow at the beginning of acute angiography, at the end of acute angiography, and at the second angiogram after 24-36 hours, in patients allocated to rescue $P T C A$ and primary PTCA.

minutes. There were no severe complications during transport. In the ambulance no patients died, two patients had to be cardioverted because of ventricular arrhythmias, two patients received atropine because of bradycardia, and the dosage of the glyceryl trinitrate infusion had to be decreased in six patients because of hypotension. Acute transport was withheld in three patients. In one patient (rescue PTCA) an echocardiogram was taken because of suspicion of aortic dissection. At the end of the echocardiography (there were no signs of aortic dissection) the patient showed signs of reperfusion on the ECG. Because of the long delay and the ECG signs of reperfusion it was decided that acute transport was no longer indicated. In two patients allocated to primary PTCA the haemodynamic situation of the patient impeded acute transport, and thrombolytic treatment was given by the referring cardiologist.

Of the 146 patients who came to Maastricht, 143 underwent angiography. In 128 patients angiography took place without delay; in 15 patients there was a delay of 60 minutes or more (mean 83 minutes) from arrival at Maastricht until start of angiography, because the catheterisation room was not immediately available when the patients arrived. In three patients immediate angiography was not possible; by the time the catheterisation laboratory was ready, immediate angiography was no longer considered to be indicated because of the time delay and the presence of non-invasive signs of reperfusion. The majority of patients were transferred back to the referring centre the next day. Because of a shortage of hospital beds in Maastricht, 33 patients had to be transferred back after coronary angiography as soon as their clinical situation had stabilised. The transport from the PTCA centre back to the referring centre was without complications in all cases.

\section{ANGIOGRAPHY}

Acute angiography was performed in 143 patients. In the rescue PTCA group TIMI 3 flow was seen at the first angiogram in 41 patients (57\%), and TIMI 2 flow was present in 10 patients $(14 \%)$. This means that patency of the infarct related coronary artery (TIMI 2 or 3 flow) was obtained by alteplase in 51 patients $(71 \%)$ at 90 minutes after initiation of the thrombolytic treatment. Rescue PTCA was performed in $14 / 20$ patients with TIMI 0 or 1 flow, and acute PTCA was performed in 5/10 patients with TIMI 2 flow and in one patient with TIMI 3 flow. In the remaining seven patients with TIMI 0 or 1 flow PTCA was not performed for technical reasons, usually because of the small diameter of the infarct related vessel. Acute PTCA was successful in $18 / 20$ patients $(90 \%)$ with a stent implanted in three patients. At the end of the procedure TIMI 3 flow was obtained in 58 patients and TIMI 2 flow in six patients (fig 3). In the primary PTCA group the infarct related coronary artery appeared to be occluded (TIMI 0 or 1 flow) in 55 patients, and TIMI 2 flow was present in nine patients. Primary PTCA was performed in 52/55 patients with TIMI 0 or 1 flow, and in eight patients with TIMI 2 flow. TIMI 3 flow was present from the beginning of the angiography in nine patients, and PTCA was performed in two patients. PTCA was successful in 60/63 patients (95\%), with a stent implanted in 13 patients. At the end of the procedure TIMI 3 flow was obtained in 66 patients and TIMI 2 flow in three patients. Second angiography, scheduled 24-36 hours after inclusion, was done in 112 patients, with high patency rates in all groups (fig 3). Second angiography was not performed in 31 patients. The reasons not to perform second angiography were: patients transferred back immediately after the first angiogram (12 patients); no consent for second angiography (seven patients); sheath already removed (two patients); and angiography not possible or considered not to be indicated on clinical grounds (10 patients).

\section{CLINICAL COURSE}

There were no significant differences in the clinical course during the first 42 days between the three treatment groups (table 2). The clinical end point of the study (death or recurrent myocardial infarction within 42 days) was reached in 12 patients $(16 \%)$ in the thrombolysis group, in 10 patients $(14 \%)$ in the rescue PTCA group, and in six patients $(8 \%)$ in the primary PTCA group. A total of seven patients suffered a stroke within 42 days; in three patients the stroke was haemorrhagic. The incidence of recurrent ischaemia, late PTCA, and $\mathrm{CABG}$ was highest in the thrombolysis group, lower in the rescue PTCA group, and lowest in the primary PTCA group (table 2). Severe bleeding complications were not observed; the incidence of minor bleeding complications was higher in the rescue PTCA group $(21 \%)$ than in the other two groups (11\%). The clinical course was uncomplicated in the majority of patients. Transient severe hypotension (four patients) and signs of severe heart failure (eight patients) were observed only in a minority of the patients. The incidence of ventricular arrhythmias did not 
Table 2 Clinical course during one year follow up

\begin{tabular}{llll}
\hline & Thrombolysis & $\begin{array}{l}\text { Thrombolysis }+ \\
\text { PTCA }\end{array}$ & $\begin{array}{l}\text { Primary } \\
\text { PTCA }\end{array}$ \\
\hline Number of patients & 75 & 74 & 75 \\
Deceased & $6(5)$ & $7(6)$ & $9(5)$ \\
Thrombotic stroke & $1(1)$ & $2(1)$ & $2(2)$ \\
Haemorrhagic stroke & $1(1)$ & $2(2)$ & $0(0)$ \\
Recurrent infarction & $9(7)$ & $5(4)$ & $4(1)$ \\
Late PTCA/CABG & $29(23)$ & $9(17)$ & $10(6)$ \\
Recurrent ischaemia only & $10(6)$ & $38(44)$ & $47(58)$ \\
None of the above & $33(48)$ & & \\
\hline
\end{tabular}

Data are at one year follow up. Figures in parentheses are at 42 days' follow up.

${ }^{\star}$ Recurrent ischaemia without infarction and not followed by intervention (PTCA/CABG).

differ among the treatment groups, and was of a magnitude that could be expected from a group of patients with extensive myocardial infarction.

ONE YEAR FOLLOW UP

Results of one year follow up are presented in table 2. The clinical course from 42 days up to one year follow up was uneventful in the majority of patients. Any event (mortality, stroke, recurrent infarct, PTCA, CABG, or recurrent ischaemia) between 42 days and one year was observed in 15 patients in the thrombolysis group, versus six patients in the rescue PTCA group and 11 patients in the primary PTCA group (differences not significant). In general, one year mortality and morbidity was relatively low in these patients who were admitted with extensive ischaemia and suffering from large myocardial infarctions.

\section{PATIENT LOG}

A patient log was recorded in all participating hospitals. A total of 1267 patients with acute myocardial infarction were admitted at the participating centres during the period of patient recruitment. Reasons not to include patients were: no indication for thrombolytic treatment because of patient delay or absence of ECG abnormalities; contraindications for thrombolytic treatment; or absence of signs of extensive ischaemia with total ST segment deviation not reaching $1.5 \mathrm{mV}$ or $15 \mathrm{~mm}$. In this last group the patients were treated with thrombolytic treatment, if indicated, but acute transport to the PTCA centre was not undertaken unless the clinical situation required such action.

\section{Discussion}

TREATMENT DELAY

Mean delay from onset of symptoms to hospital admission was on average 90 minutes, a delay that correlates well with results of other trials in patients with acute myocardial infarction in Europe, ${ }^{24}{ }^{25}$ and compares favourably to the delay observed in the global use of strategies to open occluded coronary arteries (GUSTO IIb) trial. ${ }^{13}$ This is of importance because the efficacy of reperfusion strategies is strongly dependent on total ischaemia time. Mean delay from randomisation to start of angiography was 85 minutes in the primary PTCA group. On average, primary PTCA could be started 215 minutes after onset of symptoms, a finding similar to several primary PTCA studies in which the patient was directly admitted to the PTCA centre. ${ }^{11-13}$ Delay from randomisation to start of angiography was slightly longer in the rescue PTCA group (on average 100 minutes). This was partly because of the time needed for the preparation of the bolus and infusion of the thrombolytic agent, but the fact that this was an open study might also have played a role. This bias could be avoided by giving a placebo instead of the thrombolytic agent to patients allocated to primary PTCA before transport to the PTCA centre.

LOCATION AND DISTANCE

The geographical location of the PTCA centre in Maastricht limited the number of centres that could participate (fig 1). In order to avoid excessive treatment delay participation of referral centres was limited to centres which were in the neighbourhood of the PTCA centre and which usually referred unstable patients to Maastricht. In a retrospective study in the Netherlands concerning acute transport for primary PTCA, transport was foreseen for distances up to $100 \mathrm{~km}$ with inevitably long treatment delays. ${ }^{22}$ This will probably influence the outcome of patients who undergo primary PTCA after a long treatment delay.

COMPLICATIONS DURING TRANSPORT

From the results of this trial it can be concluded that transfer of a patient with acute myocardial infarction to a PTCA centre is probably feasible and safe. The incidence of complications during transport was low, and these complications could be handled well by the experienced ambulance personnel. These results are in accordance with the results of the retrospective studies, which were done in the same region in the Netherlands, ${ }^{23}$ and in a different region in the Netherlands. ${ }^{22}$

ANGIOGRAPHY AND CLINICAL COURSE

The results of the angiograms and clinical course during follow up show a pattern similar to those of primary PTCA studies in which the patients were directly admitted to the PTCA centre. ${ }^{11}{ }^{21}$ In the rescue PTCA group 57\% of the patients had TIMI 3 flow, and as a consequence acute PTCA was not necessary. This means that the costs and the workload were lower in the rescue PTCA group than in the primary PTCA group. With regard to clinical end points, there were no significant differences between the three treatment groups. However, a trend was visible towards a lower rate of recurrent infarction in the PTCA groups. The fact that after thrombolytic treatment a significant residual stenosis remains present in the majority of cases might be the explanation for this finding. Total mortality and morbidity was low in this group of patients, especially when taking into account that this was a patient group with extensive ischaemia on the admission ECG.

FUTURE STUDIES

This pilot study was designed as a safety and feasibility study, so conclusions about the efficacy of the three regimens are not possible, 
because of the low number of patients included. All centres in this region of the Netherlands (Southern Limburg) participated in this study. This resulted in inclusion of 224 patients in two years. From the results it can be calculated that a minimum of 600 patients per treatment group will be needed to discover relevant differences between thrombolytic treatment alone versus primary PTCA or rescue PTCA in this setting. In the Netherlands such a study is only feasible when done at a nationwide level. Presently, a nationwide study is planned. However, future developments might influence the outcome of these treatment strategies in all three treatment groups.

Newer thrombolytic agents with high patency rates will soon be available. ${ }^{24}{ }^{25}$ Thrombin inhibitors or glycoprotein IIb/IIIa receptor antagonists might either replace heparin or be added to heparin, leading to higher patency and lower reocclusion rates. ${ }^{26} 27$ This will probably improve the outcome of patients treated with thrombolysis, which will decrease the need for rescue PTCA. On the other hand, implementation of the new generation of stents will probably have a positive effect on the long term success rate of both primary and rescue PTCA. ${ }^{28}{ }^{29}$ The net effect of these ameliorations will have to be awaited.

CONCLUSIONS

Acute transport for rescue PTCA or primary PTCA in patients with extensive myocardial infarction is feasible and safe. Efficacy of rescue PTCA or primary PTCA in this setting will have to be tested in larger series. The results of these trials will have to be awaited before transfer of patients in the acute phase to a PTCA centre can be implemented as "routine treatment" for patients with extensive myocardial infarction.

The following centres participated in this study. University Hospital, Maastricht (PTCA centre): FW Bär, SH Braat, EC Cheriex, JM van Dantzig, WR Dassen, PA Doevendans, K den Dulk, H Frank, AH Lousberg, ED de Muinck, GVA van Ommen, AJM Oude Ophuis, J Smeets, J Stappers, JB de Swart, F Vermeer, MA Vos, C de Zwaan; Hospital De Wever \& Grego$\mathrm{F}$ Vermeer, MA Vos, C de Zwaan; Hospital De Wever \& Grego-
rius, Brunssum/Heerlen: E vd Berg, J Lunde, HA Kragten, J rius, Brunssum/Heerlen: E vd Berg, J Lunde, HA Kragten, J
Tjan, J Vermaat, C Vincent; St Jozef Hospital, Kerkrade: AG Tjan, J Vermaat, C Vincent; St Jozef Hospital, Kerkrade: AG Boehmer; Laurentiusziekenhuis Roermond: CJ Werter, A Mattart, E van Nes, E Göbel; Maasland Hospital, Sittard/Geleen: have been possible without the collaboration of the ambulance have been possible without the collaboration of the ambulance
personnel in the region of Limburg, the personnel of the personnel in the region of Limburg, the personnel of the
catheterisation laboratory, and the staff and the nurses of all participating centres.

1 Lincoff AM, Topol EJ. Illusion of reperfusion: does anyone achieve optimal reperfusion during acute myocardial infarction? Circulation 1993;87:1792-805.

2 Simoons ML, Serruys PW, van den Brand M, et al. Early thrombolysis in acute myocardial infarction: limitation of infarct size and improved survival. $\mathcal{F}$ Am Coll Cardiol 1986; 7:717-28.

3 Fibrinolytic Therapy Trialists' Collaborative Group. Indications for thrombolytic therapy in suspected acute myocardial infarction: collaborative overview of early mortality and major morbidity results from all randomised trials of more than 1000 patients. Lancet 1994;i:311-22.

4 De Jaegere PP, Arnold AA, Balk AH, et al. Intracranial hemorrhage in association with thrombolytic therapy: incidence and clinical predictive factors. $\mathcal{F}$ Am Coll Cardiol 1992;2: 289-94.

5 GUSTO Angiographic Investigators. The effects of tissue plasminogen activator, streptokinase, or both on coronary artery patency, ventricular function, and survival after acute myocardial infarction. $N$ Engl f Med 1993;329:67382.
6 Califf RM, Topol EJ, Stack RS, et al. Evaluation of combination thrombolytic therapy and timing of cardiac catheterization in acute myocardial infarction: results of thrombolysis and angioplasty in myocardial infarction

phase 5 randomized trial. Circulation 1991;83:1543-56.

O'Keefe JH Jr, Rutherford BD, McConahay, et al. Early and late results of coronary angioplasty without antecedent thrombolytic therapy for acute myocardial infarction. $A m \mathcal{F}$ Cardiol 1989;64:1221-30.

8 Rothbaum DA, Linnemeier TJ, Landin RJ, et al. Emergency percutaneous transluminal coronary angioplasty in acute myocardial infarction: a 3 year experience. f $\mathrm{Am}$ Coll Cardiol 1987;10:264-72.

9 Kahn JK, Rutherford BD, McConahay DR, et al. Catheterization laboratory events and hospital outcome with direct angioplasty for acute myocardial infarction. Circulation 1990;82:1910-15.

10 Grines CL, Browne KF, Marco J, et al, for the Primary Angioplasty in Myocardial Infarction Study Group. A Angioplasty in Myocardial Infarction Study Group. A comparison of immediate angioplasty with thrombolytic 1993;328:673-9.

11 Zijlstra F, de Boer MJ, Hoorntje JCA, et al. A comparison of immediate coronary angioplasty with intravenous streptokinase in acute myocardial infarction. $N \mathrm{Engl} f \mathrm{Med}$ 1993;328:680-4

12 Gibbons RJ, Holmes DR, Reeder GS, et al. Immediate angioplasty compared with the administration of a thrombolytic agent followed by conservative treatment for myocardial infarction. $N$ Engl F Med 1993;328:685-91.

13 GUSTO IIb Angioplasty Substudy Investigators. A clinical trial comparing primary coronary angioplasty with tissue plasminogen activator for acute myocardial infarction. $N$ Engl f Med 1997;336:1621-8.

14 TIMI Study Group. Comparison of invasive and conservative strategies after treatment with intravenous tissue plasminogen activator in acute myocardial infarction: results of the thrombolysis in myocardial infarction (TIMI) phase II the thrombolysis in myocardial infarction
trial. N Engl $\mathcal{F}$ Med 1989;320:618-27.

15 Hartzler GO, Rutherford BD, McConahay DR, et al. Percutaneous transluminal coronary angioplasty with and without thrombolytic therapy for treatment of acute without thrombolytic therapy for treatment of
myocardial infarction. Am Heart $\mathcal{F} 1983 ; 106: 965-73$.

16 Abbottsmith CW, Topol EJ, George BS, et al. Fate of patients with acute myocardial infarction with patency of the infarct-related vessel achieved with successful thrombolysis versus rescue angioplasty. $\mathcal{F} \mathrm{Am}$ Coll Cardiol 1990;16:770-8.

17 O'Neill WW, Weintraub R, Grines CL, et al. A prospective, placebo-controlled, randomized trial of intravenous streptokinase and angioplasty versus lone angioplasty therapy of acute myocardial infarction. Circulation 1992;86:1710-17.

18 Ellis SG, Ribeiro da Silva E, Heyndricks GR, et al, for the RESCUE Investigators. Randomized comparison of rescue angioplasty with conservative management of patients with early failure of thrombolysis for acute anterior myocardial infarction. Circulation 1994;90:2280-4.

19 Holmes DR, Gersh BJ, Bailey KR, et al. Emergency "rescue" percutaneous transluminal coronary angioplasty "rescue" percutaneous transluminal coronary angioplasty
after failed thrombolysis with streptokinase. Circulation after failed thror

20 Califf RM, Topol EJ, George BS, et al. Characteristics and outcome of patients in whom reperfusion with intravenous tissue-type plasminogen activator fails: results of the thrombolysis and angioplasty in myocardial infarction (TAMI) trial. Circulation 1988;77:1090-9.

1 Bär FW, Oude Ophuis AJM, Frederiks J, et al. Rescue PTCA following failed thrombolysis and primary PTCA: a retrospective study of angiographic and clinical outcome. fournal of Thrombosis and Thrombolysis 1997;4:281-8.

22 Zijlstra F, van't Hof AWJ, Leem AL, et al. Transferring patients for primary angioplasty: a retrospective analysis of 104 selected high risk patients with acute myocardial infarction. Heart 1997;78:333-6.

23 Oude Ophuis AJM, Bär FW, Vermeer F, et al. Early referral for intentional rescue PTCA after initiation of thrombolytic therapy in patients admitted to a community hospital because of a large acute myocardial infarction. Am Heart $\mathcal{f}$. [In press.]

24 Bär FW, Meyer J, Vermeer F, et al. Comparison of saruplase and alteplase in acute myocardial infarction. Am $\mathcal{f}$ Cardiol 997:79:727-32.

25 Den Heijer P, Vermeer F, Ambrosini, et al. Evaluation of a weight-adjusted single-bolus plasminogen activator in patients with myocardial infarction: a double blind randomized angiographic trial of lanoteplase versus alteplase. Circulation 1998;98:2117-25.

26 Topol EJ, for the GUSTO Investigators. A comparison of recombinant hirudin with heparin for the treatment of acute coronary syndromes. N Engl f Med 1996;335:77582.

27 EPIC Investigators. Use of a monoclonal antibody directed against the platelet glycoprotein IIb/IIIa receptor in high risk coronary angioplsty. N Engl F Med 1993;330:956-61.

28 Suryapranata H, Hoorntje JCA, Boer MJ de, et al. Randomized comparison of primary stenting with primary Randomized comparison of primary stenting with primary
balloon angioplasty in acute myocardial infarction. Circulaballoon angioplasty
tion 1997;96:I-327.

29 Gibson M, Rizzo MJ, McLean C, et al. Adjunctive stenting following thrombolysis in TIMI $10 \mathrm{~A}$ and B. Circulation 1997;96:I-328. 